\title{
Desafios no âmbito do planejamento e da difusão de iniciativas de turismo sustentável em uma Unidade de Conservação brasileira
}

\section{Challenges in the scope of planning and diffusion of sustainable tourism initiatives in a Brazilian Conservation Unit}

Desafios en la planificación y difusión de iniciativas de turismo sostenible en una Unidad de Conservación brasileña

Dyego de Oliveira Arruda ${ }^{1}$

Beatriz Boaretto Oliveira ${ }^{2}$

Milton Augusto Pasquotto Mariani ${ }^{3}$

Maurílio Barbosa de Oliveira da Silva ${ }^{4}$

${ }^{1}$ Pós-doutor em Administração pela Universidade Federal de Mato Grosso do Sul (UFMS). Doutor em Administração de Organizações pela Universidade de São Paulo (USP). Professor do quadro permanente do Centro Federal de Educação Tecnológica Celso Suckow da Fonseca (Cefet/RJ), em cursos de graduação e no Programa de PósGraduação em Relações Étnico-Raciais (PPRER). Tem interesse e experiência nas seguintes temáticas de pesquisa: políticas públicas e ações afirmativas; gestão da diversidade.

E-mail: dyego.arruda@gmail.com, Orcid: http://orcid.org/0000-0002-9514-284X

${ }^{2}$ Graduanda em Administração pelo Centro Federal de Educação Tecnológica Celso Suckow da Fonseca (Cefet/RJ). E-mail: boaretto.beatriz@gmail.com, Orcid: http://orcid.org/0000-0003-3450-4349

${ }^{3}$ Pós-doutor em Administração e doutor em Geografia Humana pela Universidade de São Paulo (USP). Professor do quadro permanente da Universidade Federal de Mato Grosso do Sul (UFMS), em cursos de graduação e nos Programas de Pós-Graduação em Administração (PPGAD) e Estudos Fronteiriços (PPGEF). Tem interesse e experiência nas seguintes temáticas de pesquisa: turismo; desenvolvimento local/regional; economia solidária. E-mail: miltmari@terra.com.br,

Orcid: http://orcid.org/0000-0001-9485-0150

${ }^{4}$ Doutorando em Administração pela Universidade Estadual de Campinas (Unicamp). Mestre em Administração pela Universidade Federal de Mato Grosso do Sul (UFMS). Tem interesse e experiência nas seguintes temáticas de pesquisa: turismo; métodos qualitativos; Iramuteq. E-mail: barbosamaurilio@hotmail.com, Orcid: http://orcid.org/0000-0002-8498-3010 
Resumo: : O presente artigo tem como propósito analisar os desafios do planejamento e implantação de iniciativas de turismo sustentável em uma Unidade de Conservação (UC) brasileira: o Parque Natural Municipal do Açude da Concórdia (PaNaMAC). Foram conduzidas quatro entrevistas com atores institucionais da UC, ao passo que também se realizou a coleta de comentários publicados na página do TripAdvisor, na internet, por visitantes que estiveram no PaNaMAC. Os dados foram sistematizados com o uso do software Iramuteq e submetidos à análise de conteúdo. Percebeu-se que o PaNaMAC tem potencial para iniciativas de turismo sustentável, principalmente em função de seus ativos ambientais. Os turistas percebem o local como um atrativo em que é possível a prática de atividades conectadas com a perspectiva do turismo sustentável. Porém constatou-se que o poder público é um dos principais causadores dos empecilhos para a difusão do turismo sustentável no parque.

Palavras-chave: planejamento; turismo sustentável; unidades de conservação; sustentabilidade; Iramuteq.

\begin{abstract}
The purpose of this article is to analyze the challenges of planning and implementing of sustainable tourism initiatives in a Brazilian Conservation Unit: the Municipal Natural Park of Açude da Concórdia (PaNaMAC). Four interviews were conducted with institutional actors from the Conservation Unit, as well as the collection of comments published on the TripAdvisor webpage by visitors who were at PaNaMAC. The collected data were systematized using Iramuteq software and submitted to content analysis. We perceive that PaNaMAC has potential for sustainable tourism initiatives, mainly due to the environmental assets that the park has. Tourists perceive the place as a tourist attraction in which it is possible to practice activities connected with the perspective of sustainable tourism. However, it was found that the main impediments to the effective diffusion of sustainable tourism in the park are mainly related to the performance of the public power.
\end{abstract}

Keywords: planning; sustainable tourism; conservation units; sustainability; Iramuteq.

Resumen: Este artículo tiene como objetivo analizar los desafíos de planificar e implementar iniciativas de turismo sostenible en una Unidad de Conservación de Brasil: el Parque Natural Municipal de Açude da Concórdia (PaNaMAC). Se realizaron cuatro entrevistas con actores institucionales de la Unidad de Conservación, mientras que la colección de comentarios publicados por visitantes que estuvieron en PaNaMAC también fue realizada en la página de TripAdvisor, en la internet. Los datos fueron sistematizados usando el software Iramuteq y sometidos a análisis de contenido. Se observó que el PaNaMAC tiene potencial para iniciativas de turismo sostenible, principalmente debido a sus activos ambientales. Los turistas perciben el lugar como una atracción en la que es posible practicar actividades relacionadas con la perspectiva del turismo sostenible. Sin embargo, se descubrió que el gobierno es una de las principales causas de obstáculos para la propagación del turismo sostenible en el parque.

Palabras clave: planificación; turismo sostenible; unidades deconservación; sostenibilidad; Iramuteq. 


\section{INTRODUÇÃO}

Quais os dilemas que cercam os processos de elaboração e difusão de iniciativas de turismo sustentável em uma Unidade de Conservação (UC) brasileira?

Partindo do supracitado problema de pesquisa, o presente artigo tem como objetivo compreender os desafios no âmbito de planejamento e implantação de iniciativas de turismo sustentável no Parque Natural Municipal do Açude da Concórdia (PaNaMAC), uma Unidade de Conservação localizada no município de Valença, no sul do Estado do Rio de Janeiro.

Em suma, o PaNaMAC, caso que será explorado no presente estudo, foi criado no ano de 2001, com a intenção prioritária de estimular práticas de preservação da Mata Atlântica (bioma típico da região, atualmente sob forte pressão e ameaça de degradação), bem como instigar atividades de recreação, lazer, educação ambiental e pesquisa científica ligadas à sustentabilidade e ao desenvolvimento regional. Consta nos objetivos prioritários do PaNaMAC o estímulo a ações de turismo sustentável na área que compõe o parque.

O PaNaMAC tem uma área total de 40 hectares repletos de densa e preservada vegetação, numa dinâmica em que somente o Açude da Concórdia apresenta uma superfície de pouco mais de 13 hectares, ocupando, portanto, uma área considerável do parque. Vale ressaltar que, para além da vegetação de Mata Atlântica, o parque sob análise abriga também uma rica e diversificada fauna, sem contar o Açude da Concórdia enquanto um recurso hídrico de considerável relevância, inclusive para a prática de atividades de lazer e turismo, sobretudo pela comunidade local.

Entende-se que, ao se lançar luz nos detalhes e desafios das iniciativas de turismo sustentável no PaNaMAC, é possível que se tenham elementos para se (re)programar o uso adequado e sustentável da UC sob análise, indicando caminhos a partir das quais outras UCs brasileiras podem ser adequadamente geridas e, nesse ínterim, recepcionar, sem maiores adversidades e impactos, atividades de turismo sustentável.

Além disso, deve-se salientar que, do ponto de vista teórico, o artigo discute o conceito de turismo sustentável, que é um tema salutar, 
sobretudo em função da tomada de importância cada vez mais significativa da sustentabilidade enquanto elemento norteador de pesquisas, reflexões e planejamento de atividades socioeconômicas.

De todo modo, o que é turismo sustentável? De que maneira tal construto teórico relaciona-se com o conceito de sustentabilidade e pode ser planejado e implementado em UCs? No tópico que segue, há um esforço de discussão em torno das supracitadas questões.

\section{TURISMO SUSTENTÁVEL E AS UNIDADES DE CONSERVAÇÃO}

O fenômeno turístico está diretamente relacionado com o desejo das pessoas de viajar e, por conseguinte, conhecer espaços distintos de seus locais de residência habitual. Sabe-se que, contemporaneamente, os turistas viajam motivados por uma série de fatores, entre os quais (BARRETO, 2006; WONG; LAW; ZHAO, 2018): acessar fontes de alimentos e localidades seguras; suprir carências afetivas (visitar familiares e amigos, por exemplo); exercitar a religiosidade; interagir com outras pessoas; conhecer novas culturas e hábitos; além das motivações relacionadas ao trabalho, estudos ou lazer.

Com o desenvolvimento socioeconômico de determinados países, houve uma melhora no padrão de vida das pessoas, o que fez com que o fluxo de turistas, no mundo, fosse ampliado em níveis consideráveis (INCHAUSTI-SINTES, 2015). Segundo dados consolidados do ano de 2018, o fluxo mundial de turistas foi de pouco mais de 1,3 bilhão de pessoas - valor $30 \%$ maior em relação à quantidade de pessoas que viajaram mundo afora no ano de 2008 (UNWTO, 2018). Todo esse contingente de turistas fez com que o setor de viagens e turismo, no ano de 2018, fosse o responsável por 10,4\% de todo o Produto Interno Bruto (PIB) mundial, numa dinâmica em que passa dos 319 milhões o quantitativo de empregos gerados, direta ou indiretamente, pelo setor de viagens e turismo (WTTC, 2019).

Muito embora o turismo seja o responsável por proporcionar renda e ocupação para uma série de localidades, é necessário considerar também que tal atividade pode implicar um uso excessivo dos recursos naturais, resultando em adversidades, tais como (SOUSA; AQUINO, 2007): desmatamento, perda da biodiversidade e das culturas locais, aumento da poluição, 
Desafios no âmbito do planejamento e da difusão de iniciativas de turismo sustentável em uma Unidade de Conservação brasileira

além da "invasão" e consequente destruição de áreas naturais passíveis de proteção.

Desse modo, faz-se necessário estimular iniciativas de turismo sustentável, com o propósito de que o fenômeno do turismo represente uma conformação de benefícios econômicos, sociais, ambientais e políticos aos territórios, minimizando os impactos, sobretudo de ordem socioambiental, que o fluxo de turistas nas áreas naturais pode representar (HIGGINSDESBIOLLES, 2018).

O conceito de turismo sustentável surgiu no final da década de 1980, na mesma época em que se consagrou, em um relatório da ONU denominado Nosso Futuro Comum, a ideia central do desenvolvimento sustentável, que remetia à necessidade de se manterem as atividades socioeconômicas contemporâneas sem que se esgotasse a disponibilidade de recursos (naturais, humanos, culturais e econômicos), para que as gerações futuras também pudessem garantir seus respectivos modos de vida (UNITED NATIONS [UN], 1987; NILSSON; GRIGGS; VISBECK, 2016).

Assim sendo, o turismo sustentável surge como uma atividade que deve ser estruturada e implementada partindo da premissa de que se deve garantir as necessidades dos turistas e das comunidades receptoras, ao mesmo tempo em que se protege e se amplia o conjunto de oportunidades para o futuro (UNWTO, 1998).

Pode-se dizer que, em função das características dos modos de vida contemporâneos, há fatores que fazem com que o turismo sustentável figure como algo cada vez mais importante e necessário, de tal modo que, entre tais fatores, podem-se destacar quatro principais (MOWFORTH; MUNT, 2015): (I) o aumento da insatisfação com os produtos turísticos predatórios, poluidores e eminentemente insustentáveis; (II) a ampliação da consciência ambiental e da sensibilidade sociocultural, por parte dos visitantes; (III) o reconhecimento do potencial turístico de áreas com recursos socioambientais e culturais preciosos e vulneráveis; e (IV) a mudança de atitude por parte de agências e operadoras de turismo, que cada vez mais tentam se organizar para oferecer produtos turísticos sustentáveis aos clientes.

De todo modo, para que o turismo sustentável seja uma atividade possível, é indispensável um processo de organização e planejamento, que 
envolva os atores direta ou indiretamente relacionados com o trade turístico, os gestores públicos de meio ambiente e turismo, além das comunidades locais (MONGE; PERALES, 2016; LIU, 2003).

Em suma, os atores diretamente relacionados com o trade turístico (tais como agências e operadoras de turismo, além dos hotéis, pousadas e afins) devem ser os responsáveis por "formatar" uma proposta de valor coerente com a lógica do turismo sustentável, entregando-a aos potenciais visitantes das destinações turísticas (LIU, 2003). Nesse ínterim, Sigala (2008), Urt, Arruda e Mariani (2018) sugerem que as organizações que lidam com o turismo sustentável devem ter um conjunto de princípios e valores coerentes com a lógica do desenvolvimento sustentável (tais como códigos de ética e conduta socioambiental, práticas de responsabilidade social, comércio justo e afins), sendo, inclusive, as responsáveis por estimular práticas sustentáveis nos visitantes.

Não obstante, as organizações que, mesmo de modo indireto, se relacionam com o trade turístico (tais como empresas de transporte, restaurantes e demais prestadores de serviços) também devem, em alguma medida, envolver-se com a lógica do desenvolvimento sustentável, o que poderia fazer com que os princípios da sustentabilidade se manifestem como valores e práticas arraigadas nas localidades em que as iniciativas de turismo sustentável, em específico, aconteçam (CETIN, 2015).

Os gestores públicos de meio ambiente e turismo, por seu turno, devem ser os protagonistas das políticas públicas que resultem em estímulos para que o turismo sustentável efetivamente se materialize e alcance os seus benefícios potenciais (HATIPOGLU; ALVAREZ; ERTUNA, 2016). Em resumo, as políticas públicas de meio ambiente e turismo sustentável devem consolidar (MELLON; BRAMWELL, 2016): (I) planejamentos, com estratégias factíveis e metas, para a condução e o estímulo ao turismo sustentável; (II) reconhecimento das boas práticas socioambientais por parte das organizações presentes nas localidades, sobretudo no escopo do turismo sustentável; (III) análises e definições de capacidade de carga para que a prática do turismo ocorra sem muitos impactos ao meio ambiente, sobretudo nas áreas de preservação (tais como as Unidades de Conservação); (IV) estímulos para que as organizações direta ou indiretamente inseridas no trade turístico adotem 
códigos de ética e conduta socioambiental na gestão de seus negócios; (V) barreiras para que a localidade não receba atividades socioeconômicas eminentemente poluidoras e degradantes ao meio ambiente; e (VI) incentivos para que os vários agentes do trade turístico atuem de modo coordenado e, se possível, de modo colaborativo e sinérgico, no escopo do oferecimento de atividades de turismo sustentável aos visitantes.

Por fim, deve-se ainda registrar que as comunidades locais devem ser diretamente impactadas pelos benefícios decorrentes do turismo sustentável (tais como a geração de ocupação e renda, além da valorização da cultura e dos hábitos locais), numa dinâmica em que os residentes se sintam estimulados a serem artífices dos processos de preservação dos recursos ambientais e socioculturais que particularizam a localidade (MURESAN et al., 2016).

Nesse ínterim, Damas (2020) salienta que é um risco permitir e até estimular que as práticas de turismo sustentável nas localidades ocorram sem a participação e integração da comunidade local. Ainda segundo o autor em análise, quando o turismo sustentável se materializa sem que as comunidades locais estejam cientes desse processo, são enormes os riscos de especulação imobiliária e deterioração dos costumes e modos de vida tradicionais, numa dinâmica em que, em última análise, tais aspectos acabam por penalizar os residentes locais, implicando até mesmo a expulsão de tais sujeitos dos territórios nos quais tradicionalmente viveram.

Sabe-se que as Unidades de Conservação (UCS) representam terreno fértil para a proliferação de iniciativas de turismo sustentável (SANTOS; MELO; LEITE, 2019). No Brasil, o próprio dispositivo legal que norteia a gestão de UCs reconhece que tais áreas são potenciais receptáculos de atividades de turismo sustentável, uma vez que tal modalidade de turismo - se bem planejada - implica permitir que as pessoas conheçam os recursos da fauna e flora protegidos, sem que ocorram impactos significativos e degradantes para a UC (TEMOTEO; BRANDÃO; CRISPIM, 2018).

Contemporaneamente, sobretudo em função dos modos de vida nas cidades e metrópoles, há uma crescente busca, por parte dos visitantes, por destinos turísticos mais calmos, afastados dos centros urbanos, em que seja possível um contato permanente com a natureza e com culturas peculiares (LEE; JAN, 2018). Nesse ínterim, Melo, Monteiro e Brito (2018) salientam 
que as práticas de turismo sustentável em UCs têm um potencial expressivo de crescimento, uma vez que a própria gênese dessa modalidade de turismo atende anseios do turista contemporâneo, que quer conhecer ativos ambientais preservados e, na medida do possível, sentir-se responsável por contribuir com a manutenção desses recursos.

Em apertada síntese, parte-se da perspectiva de que planejamento e implementação adequados do turismo sustentável nas UCs carecem dos seguintes aspectos (TEMOTEO; BRANDÃO; CRISPIM, 2018; MELO; MONTEIRO; BRITO, 2018; SANTOS; MELO; CARDOSO-LEITE, 2019): (a) existência de uma política pública coerente e comprometida com a adequada difusão do turismo sustentável; (b) a existência de monitoramento e avaliações da capacidade de carga, para que o turismo não implique pressão e degradação dos ativos ambientais das UCs; (c) o envolvimento das comunidades locais na atividade do turismo sustentável nas UCs; e (d) clareza quanto à importância de se respeitar e difundir princípios relacionados à sustentabilidade nas destinações turísticas.

Rodrigues, Moreira e Freire (2018) pontuam que uma gestão inadequada das atividades que ocorrem nas UCs, em muitas circunstâncias, deve-se à inexistência de recursos financeiros e humanos para o monitoramento e a proteção do território, sem contar o descaso dos gestores públicos nacionais e regionais, que, em muitas circunstâncias, desconhecem o próprio conceito de turismo sustentável, o que, notadamente, impedirá que uma agenda para o adequado desenvolvimento dessa modalidade de turismo nas UCS efetivamente se materialize.

Agora, dadas as reflexões acima sumarizadas, a pergunta que por ora surge é a seguinte: quais as características dos processos de planejamento e implementação das iniciativas de turismo sustentável no Parque Natural Municipal do Açude da Concórdia (PaNaMAC), uma UC localizada no sudeste brasileiro? No tópico que segue, há uma descrição dos procedimentos metodológicos que foram empregados na coleta de dados, os quais possibilitaram, em alguma medida, a estruturação de respostas e inferências que respondessem à supracitada questão. 


\section{PROCEDIMENTOS METOdOLÓGICOS}

A pesquisa empírica feita no presente estudo caracterizou-se por ter sido de abordagem qualitativa e quantitativa. Em suma, a perspectiva qualitativa justificou-se pelo fato de que compreender as nuances, contradições e desafios das iniciativas de turismo sustentável no PaNaMAC exigiu perspectivas de pesquisa flexíveis e interpretativas (MERRIAM; GRENIER, 2019). Não obstante, a abordagem quantitativa decorre do uso do software Iramuteq, que, entre uma série de funcionalidades, permite a contagem da frequência das palavras mais recorrentes em um corpus textual, conforme detalhes que serão descritos nos próximos parágrafos.

Quanto aos procedimentos técnicos de pesquisa, a investigação em tela tipificou-se como um estudo de caso, cuja ideia fundamental foi permitir a obtenção de conhecimentos minuciosos acerca de um determinado fenômeno e/ou objeto de pesquisa (YIN, 2015). Vale destacar que o caso explorado na presente investigação foi o do PaNaMAC, cuja dinâmica do turismo sustentável que é empreendido neste lócus objetivou-se compreender.

Para a coleta de dados empíricos, foram utilizadas as seguintes estratégias:

- Entrevistas com informantes-chave;

- Coleta de comentários de pessoas que visitaram o PaNaMAC e publicaram as suas percepções acerca do parque na página on-line do TripAdvisor - um portal da internet que reúne comentários e avaliações de turistas acerca de equipamentos de apoio ao turismo, tais como atrativos turísticos, hotéis, restaurantes e afins;

- Visitas in loco ao PaNaMAC, para que pudessem ser observadas as características gerais da fauna, flora, beleza cênica, além da infraestrutura de apoio aos visitantes.

As entrevistas, em específico, foram realizadas nos meses de dezembro/2018 e janeiro/2019, com 4 (quatro) informantes-chave que se relacionam diretamente com a formulação e implementação de estratégias e políticas públicas de turismo sustentável no PaNaMAC. As entrevistas foram gravadas; duraram, em média, 12 (doze) minutos e se realizaram com a anuência dos entrevistados, que assinaram um Termo de Consentimento 
Livre e Esclarecido (TCLE), concordando em participar, de modo voluntário, da pesquisa. Todas as entrevistas, depois de feitas, foram transcritas.

Como subterfúgio para a realização das entrevistas, foi utilizado um protocolo de pesquisa com questões norteadoras. Em resumo, o protocolo continha questões que se relacionavam aos seguintes aspectos do PaNaMAC: (I) história e características gerais; (II) especificidades do funcionamento; (III) nível de conhecimento dos entrevistados quanto ao conceito de turismo sustentável; (IV) possível existência de iniciativas de turismo sustentável; (V) detalhes de como a atividade do turismo sustentável eventualmente ocorre; e (VI) dinâmicas das políticas públicas de fomento ao turismo sustentável no parque.

O quadro 1 sumariza detalhes gerais dos informantes-chave que foram entrevistados. Ressalte-se que, com o propósito de preservar a identidade e garantir o anonimato dos participantes da pesquisa, foram utilizadas siglas para que cada um fosse identificado.

Quadro 1 - Características dos entrevistados

\begin{tabular}{|c|c|c|}
\hline Sigla & Função do entrevistado & Informações gerais \\
\hline E_1 & $\begin{array}{c}\text { Guarda-parque, responsável } \\
\text { pelo monitoramento da área e } \\
\text { atendimento do público externo } \\
\text { que visita a UC }\end{array}$ & $\begin{array}{c}\text { Homem, nascido na região em } \\
\text { que a UC se localiza. Conhece bem } \\
\text { a UC e a visita desde criança. Tem } \\
\text { boa compreensão dos detalhes da } \\
\text { fauna e flora da UC }\end{array}$ \\
\hline E_2 & $\begin{array}{c}\text { Membro da equipe de gestão do } \\
\text { Parque, ligado ao Instituto Estadual } \\
\text { de Meio Ambiente do Estado do } \\
\text { Rio de Janeiro (Inea/RJ) }\end{array}$ & $\begin{array}{c}\text { Homem, não conhecia a UC } \\
\text { antes de ser designado para } \\
\text { administrá-la }\end{array}$ \\
\hline E_3 & $\begin{array}{c}\text { Membro do secretariado municipal } \\
\text { de Valença, RJ, cuja atuação está } \\
\text { diretamente ligada ao Parque }\end{array}$ & $\begin{array}{c}\text { Homem, empresário da região, } \\
\text { também acumula funções na } \\
\text { administração pública local }\end{array}$ \\
\hline E_4 & $\begin{array}{c}\text { Membro do secretariado do } \\
\text { município de Valença, RJ, cuja } \\
\text { atuação está diretamente ligada ao } \\
\text { Parque }\end{array}$ & $\begin{array}{c}\text { Homem, está há pouco tempo na } \\
\text { função que desempenha }\end{array}$ \\
\hline
\end{tabular}

Fonte: dados da pesquisa. 
Quanto aos comentários dos turistas na página on-line do TripAdvisor, deve-se ponderar que tais dados foram coletados com o propósito de se explorar o modo como os visitantes "enxergam" o PaNaMAC, além dos atributos por eles valorizados. Ademais, os comentários permitiram com que se analisasse a perspectiva do turismo sustentável pela ótica dos visitantes, ou seja: foi possível perceber se tal modalidade de turismo é algo que o visitante vislumbra e de alguma forma pratica no parque.

Foram extraídos, da página do TripAdvisor, um total de 22 comentários de pessoas que visitaram o PaNaMAC nos anos compreendidos entre 2013 e 2017. Tais comentários representaram a completude de avaliações sobre o parque encontradas no TripAdvisor.

Ressalte-se que tanto as transcrições das entrevistas quanto os comentários dos visitantes representaram corpus textuais, que foram submetidos ao software Iramuteq - uma ferramenta gratuita, ancorada no software R, que permite uma organização de textos, facilitando, desse modo, o processo de análise de informações textuais (SOUZA et al., 2018).

Camargo e Justo (2013) salientam que o Iramuteq é uma ferramenta inovadora, uma vez que permite o emprego de algumas estatísticas (tais como frequência absoluta de palavras, testes de correlação e afins) para a análise do modo como as palavras, no escopo de um texto, relacionam-se umas com as outras. A partir do uso do Iramuteq é possível, por exemplo, que sejam construídas nuvens de palavras, que mostram os termos cuja ocorrência é mais comum, em um corpus textual que se queira analisar (KAMl et al., 2016).

As nuvens de palavras, além dos detalhes decorrentes dos processos de observação participante nas visitas in loco, foram submetidas a técnicas de análise de conteúdo que possibilitam a realização de interpretações e inferências, com base na criteriosa avaliação dos dados coletados e sistematizados no âmbito do estudo (BARDIN, 2002).

\section{O PANAMAC: DETALHES DO CASO EM ESTUDO}

O PaNaMAC, institucionalizado no ano de 2001, representa a primeira Unidade de Conservação (UC) do município de Valença, no sul do Estado do Rio de Janeiro, distante pouco mais de 150 quilômetros em relação à 
capital fluminense. Deve-se pontuar que o município em que a UC está sediada tem uma população estimada de pouco mais de 76 mil habitantes, distribuídos em uma área aproximada de $1.300 \mathrm{~km}^{2}$, o que resulta em uma densidade demográfica de 58 habitantes $/ \mathrm{km}^{2}$ - bem inferior em relação à densidade demográfica da capital do Rio de Janeiro, que é de mais de 5,2 mil habitantes $/ \mathrm{km}^{2}$ (IBGE, 2019).

O parque em análise é reconhecido como um território em que é possível encontrar espécies da fauna e flora típicas do bioma da Mata Atlântica, que foi permanentemente desmatado e explorado no Sudeste brasileiro. Lemos (2004), ao se debruçar em análises de vieses historiográficos, sugere que na porção sul do Estado do Rio de Janeiro, onde se encontra o município de Valença, a prevalência da monocultura do café, ao longo dos séculos XVII e XVIII, implicou significativas pressões sobre o bioma da Mata Atlântica, que foi permanentemente substituído pelas lavouras cafeeiras. Nesse ínterim, pode-se depreender que a institucionalização do PaNaMAC, além de preservar e (re)valorizar o meio ambiente e o bioma da Mata Atlântica, em particular, também implicou esforços para a recuperação de áreas outrora desmatadas e degradas pela monocultura cafeeira.

Vaz (2010) ressalta que, após o momento em que o PaNaMAC se tornou uma UC, foram objetivos prioritários do parque: (I) proteção e preservação dos resquícios do bioma da Mata Atlântica; (II) proteção à fauna e flora, em especial aos exemplares ameaçados de extinção; (III) integração de corredores ecológicos; (IV) estímulo a atividades de turismo sustentável; (V) fomento às ações de pesquisa e extensão, com viés sustentável; e (VI) proteção dos recursos hídricos do município de Valença.

Historicamente, o PaNaMAC, por abrigar o Açude da Concórdia, foi reconhecido e valorizado como o provedor de água potável para o município de Valença. Contemporaneamente, o parque fornece água apenas para um único bairro da cidade, conforme é possível de se depreender na fala de E_1, que conhece há muito tempo o território: "A água abastece o bairro de São Francisco, assim como abastecia antigamente Valença, só que, por não dar conta devido ao seu volume de água ser pouco, parou de abastecer a cidade".

Para além da relevância do PaNaMAC enquanto fonte de água potável, notou-se na fala dos entrevistados um conjunto significativo de menções 
Desafios no âmbito do planejamento e da difusão de iniciativas de turismo sustentável em uma

aos ativos ambientais do parque, o que revela que a localidade em análise é vista pelos seus gestores enquanto um importante lócus com "[...] um ambiente, um bioma, que devem ser explorados de forma sustentável", conforme salientou o entrevistado E_3.

No período compreendido entre 2001 (ano da institucionalização da UC) até fevereiro de 2013, a gestão do PaNaMAC esteve sob responsabilidade de um grupo da sociedade civil organizada, intitulado Associação de Defesa do Meio Ambiente do Médio Paraíba (AMA). Não obstante, a partir de fevereiro de 2013 até dezembro de 2017, a responsabilidade do parque passou, legalmente, para a Prefeitura Municipal de Valença. Conforme foi possível constatar nas falas dos entrevistados, os supracitados períodos foram de significativa desorganização, em que o PaNaMAC padeceu por não ter equipes de funcionários (gestores, guarda-parques e afins) e por carecer de instrumentos institucionalizados de planejamento e gestão, o que fez com que o território acabasse sofrendo pressões, principalmente sobre os ativos ambientais que o parque possui. O entrevistado $E_{-}$1, ao referir-se ao período em que o PaNaMAC esteve sob responsabilidade da prefeitura de Valença, pondera que:

[...] a prefeitura não tinha condições de fazer a manutenção adequada do parque, estava totalmente abandonado, portas arrombadas, equipamentos foram furtados, a mata estava com semblante de falecimento, não existiam animais nas proximidades. Caçadores haviam invadido o parque e moradores das redondezas estavam pescando no açude.

Em dezembro de 2017, a prefeitura de Valença, reconhecendo que não tinha competência técnica e financeira para gerir adequadamente o PaNaMAC, celebrou um Termo de Cessão de Uso com o Instituto Estadual de Meio Ambiente (Inea) - autarquia vinculada ao governo do Estado do Rio de Janeiro, cuja missão fundamental é proteger e conservar os recursos ambientais do Estado. Em síntese, o acordo em questão teve como propósito transferir, de modo voluntário, a responsabilidade pelo planejamento e gestão do PaNaMAC da Prefeitura de Valença para o Inea, por um período de cinco anos, prorrogáveis por igual período.

Constatou-se, ao longo das entrevistas com os informantes-chave, que o Termo de Cessão em tela foi encarado como sendo positivo, uma vez que 
a expertise e estrutura (financeira, técnica e de pessoal) do Inea permitiu que o PaNaMAC passasse por um processo de revitalização, conforme se nota nas falas dos entrevistados abaixo transcritas:

[...] o Inea conseguiu fazer o parque reviver, fez a obra de revitalização do parque e sua manutenção (Entrevistado E_1).

[...] com essa nova gestão do Inea, vai ter muito mais divulgação na mídia e muitas pessoas irão visitar [o parque], pois ainda há muitas pessoas que não possuem o conhecimento sobre o que pode ser encontrado na Concórdia, por falta mesmo de divulgação. Divulgação é ideal e o Inea sabe lidar com isso muito bem (Entrevistado E_4).

Na medida em que o Inea assumiu a responsabilidade pelo planejamento e gestão do PaNaMAC, percebeu-se que houve um incremento da estrutura do parque - reformas das instalações da sede; revitalização de decks e passarelas que dão acesso ao açude; preservação de espécies nativas e recuperação de áreas degradadas; além da cessão de equipe técnica (guardas-parque) para fazer o monitoramento e controle de acesso na UC, inclusive de turistas.

De todo modo, a despeito de as inferências quanto à relevância do Inea na gestão do PaNaMAC serem positivas, ainda assim percebeu-se um temor quanto ao futuro da supracitada autarquia e, por conseguinte, do incremento na gestão do parque. Em suma, notou-se que a crise fiscal pela qual passa o Brasil e o Estado do Rio de Janeiro, em particular, é constantemente citada como empecilho para que o PaNaMAC tenha a sua estrutura melhorada, de tal modo que essas dificuldades certamente implicam barreiras para o incremento de algumas atividades que eventualmente ocorrem dentro do parque, tais como o turismo sustentável.

Agora, ante os aspectos supracitados, a pergunta que por ora surge é a seguinte: como "são enxergadas" as iniciativas de turismo sustentável no escopo do PaNaMAC, pela ótica das pessoas responsáveis por planejar e gerir o parque contemporaneamente? No tópico que segue, há uma discussão em torno do supracitado aspecto. 


\subsection{Iniciativas de turismo sustentável sob a ótica dos atores institucionais entrevistados}

Ao serem questionados sobre a importância das iniciativas de turismo sustentável para o PaNaMAC, todos os informantes-chave entrevistados no presente estudo foram unânimes em afirmar que tal modalidade de turismo é relevante, devendo ser fomentada no território. Porém, ao serem questionados sobre o que acreditavam ser o turismo sustentável, percebeu-se que os entrevistados não souberam, de modo suficientemente robusto, explicar o que entendiam e, eventualmente, quais perspectivas teórico-metodológicas conheciam acerca do turismo sustentável. Em síntese, os entrevistados E_1 e E_3 alegaram não conhecer o conceito de turismo sustentável; E_2 afirmou que tal modalidade de turismo remonta exclusivamente à preservação do meio ambiente; ao passo que E_4 relatou que, para ele, turismo sustentável seria "[...] vender alguma coisa para os turistas que vão ao parque".

Assim sendo, muito em função de desconhecerem o que é turismo sustentável, os informantes-chave não conseguiram demonstrar a existência de algum tipo de planejamento estruturado e crível para a organização e o fomento a tal modalidade de turismo no parque.

Percebeu-se que não há, para o PaNaMAC, uma definição da quantidade máxima de visitantes desejável no parque, sem que houvesse algum tipo de degradação dos ativos ambientais que existem na localidade. Nos diálogos com o E_3, ficou evidente que a inexistência de dados sistematizados (tais como estudos de capacidade de carga para atividades de turismo) é uma constante no território, conforme se depreende do relato de E_3, abaixo transcrito:

[...] quando assumimos essa secretaria [ligada ao turismo, no município de Valença], não tínhamos nenhum dado histórico catalogado de eventos turísticos, de exploração turística da cidade, de hotéis, não tínhamos nada. Nós estamos fazendo um banco de dados agora, nesses últimos dois anos, mas essa parte do Parque Natural Municipal do Açude da Concórdia não temos nada.

Ademais, inexistem no PaNaMAC controles sistemáticos e criteriosos acerca do número de visitantes no parque. O que há é um livro de registro 
que as pessoas assinam, de modo voluntário, depois de percorrerem as dependências do parque.

Não se percebeu também, nos diálogos com os entrevistados, a consciência quanto às características, perfil e principais demandas dos visitantes do PaNaMAC. O que foi possível inferir, principalmente a partir das falas de E_1 e E_2, é que os visitantes se dirigem ao parque principalmente em função do açude (que possui uma beleza cênica considerável), além daqueles interessados em fazer piquenique, trilhas, leves caminhadas, sem contar os que desejam acampar.

Deve-se ponderar que não há incentivos e organização, sobretudo por parte do poder público, em prol de uma efetiva integração da comunidade local no sentido de que esta (re)conheça o PaNaMAC como um território turístico e, eventualmente, beneficie-se do desenvolvimento de tal atividade no parque. O que foi perceptível foi apenas o desejo de integrar a comunidade local ao parque, divulgando os detalhes e as ações do PaNaMAC, sobretudo às pessoas mais jovens - que são consideradas, conforme constatou-se nos diálogos que foram feitos, "[...] a geração que vai cuidar do nosso meio ambiente" (Entrevistado E_4).

Outro aspecto importante foi a constatação de que os equipamentos de apoio ao turismo no território (tais como agências de turismo, hotéis, pousadas, empresas de transporte, além de restaurantes) não reconhecem e divulgam o PaNaMAC como um atrativo em que é possível a prática de turismo sustentável. Conforme relataram os entrevistados, os visitantes que chegam ao parque buscam informações por intermédio da internet e das redes sociais (tais como Facebook), numa dinâmica em que se dirigem de modo autônomo ao parque, sem que exista uma estrutura coordenada e efetiva para "oferecer" serviços relacionados ao turismo a quem chega até Valença e, eventualmente, deseja conhecer o PaNaMAC.

A Figura 1 ilustra os principais termos que "apareceram" nos diálogos com os informantes-chave entrevistados no escopo da presente pesquisa. 
Figura 1 - Nuvem de palavras (diálogo com os entrevistados)

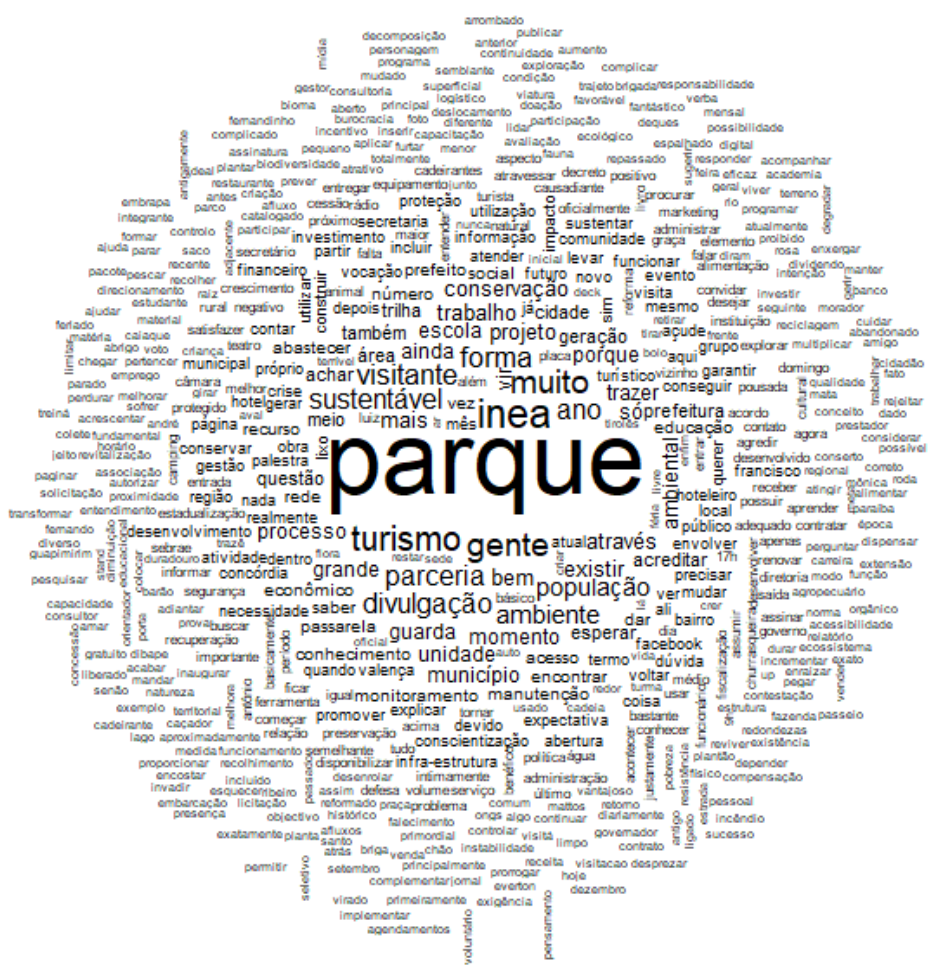

Fonte: Dados da pesquisa.

Percebe-se que o termo "parque" aparece com muita ênfase na nuvem de palavras, uma vez que as pessoas que foram entrevistadas relataram, de modo recorrente, detalhes do PaNaMAC, sobretudo no que tange às características físicas (especificidades da paisagem, estrutura de apoio e afins). Além disso, o termo "Inea" também aparece em destaque, já que os entrevistados fizeram várias menções ao atual modelo de gestão do parque, o que implica uma parceria com o Inea - conforme se explorou no tópico anterior deste artigo. Não obstante, os termos "turismo", "sustentável" e "visitantes" também são destacados na Figura 1, principalmente porque, por intermédio do roteiro de entrevistas que foi usado, os entrevistados foram estimulados a refletir em torno dessas temáticas.

$\mathrm{E}$, quanto às pessoas que já visitaram o PaNaMAC, quais aspectos são os mais relevantes, pela ótica desses visitantes? No tópico que segue, há um 
esforço de se refletir em torno desta questão, com base em comentários publicados na página on-line do TripAdvisor.

\subsection{O caso em análise, sob a ótica dos turistas}

Na página do TripAdvisor, pesquisou-se o termo "Parque Natural Municipal Açude de Concórdia", de tal modo que foram obtidas 22 avaliações.

O primeiro aspecto que chama atenção é o fato de que a última avaliação postada na página do TripAdvisor é de 2017, justamente o ano em que é celebrado o acordo com o Inea, que permitiu - ao menos em tese - um incremento da estrutura e conservação do parque, conforme se verificou nas análises decorrentes das falas dos gestores entrevistados. É possível inferir que o perfil dos turistas que mais recentemente visitam o PaNaMAC não é daqueles que geram conteúdos de modo assíduo na internet, o que explica a ausência de comentários mais recentes, acerca do parque sob análise, na página do TripAdvisor.

Dos 22 turistas que postaram comentários no TripAdvisor, 16 deles ( $72 \%$ do total) indicaram a respectiva cidade de origem, de tal modo que oito são das cidades de Valença, Rio das Flores ou Volta Redonda (que são municípios próximos do PaNaMAC); ao passo que seis são da cidade do Rio de Janeiro ou de Nova Iguaçu (este último é município integrante da região metropolitana da cidade do Rio de Janeiro). Assim sendo, nota-se que o perfil médio da maioria das pessoas que visitam o PaNaMAC é de moradores da região, que percorrem distâncias relativamente curtas para chegarem ao parque.

Quanto à avaliação feita pelos turistas, que podem atribuir uma nota ao atrativo visitado, numa escala que vai de 1 até 5 , verificou-se que o PaNaMAC apresentou uma nota média de 4,2. Desse modo, percebe-se que o parque é avaliado de modo positivo pelos visitantes.

A Figura 2 traz as palavras mais recorrentes nos comentários postados pelos turistas na página do TripAdvisor, na internet. 
Figura 2 - Nuvem de palavras (comentários dos turistas)

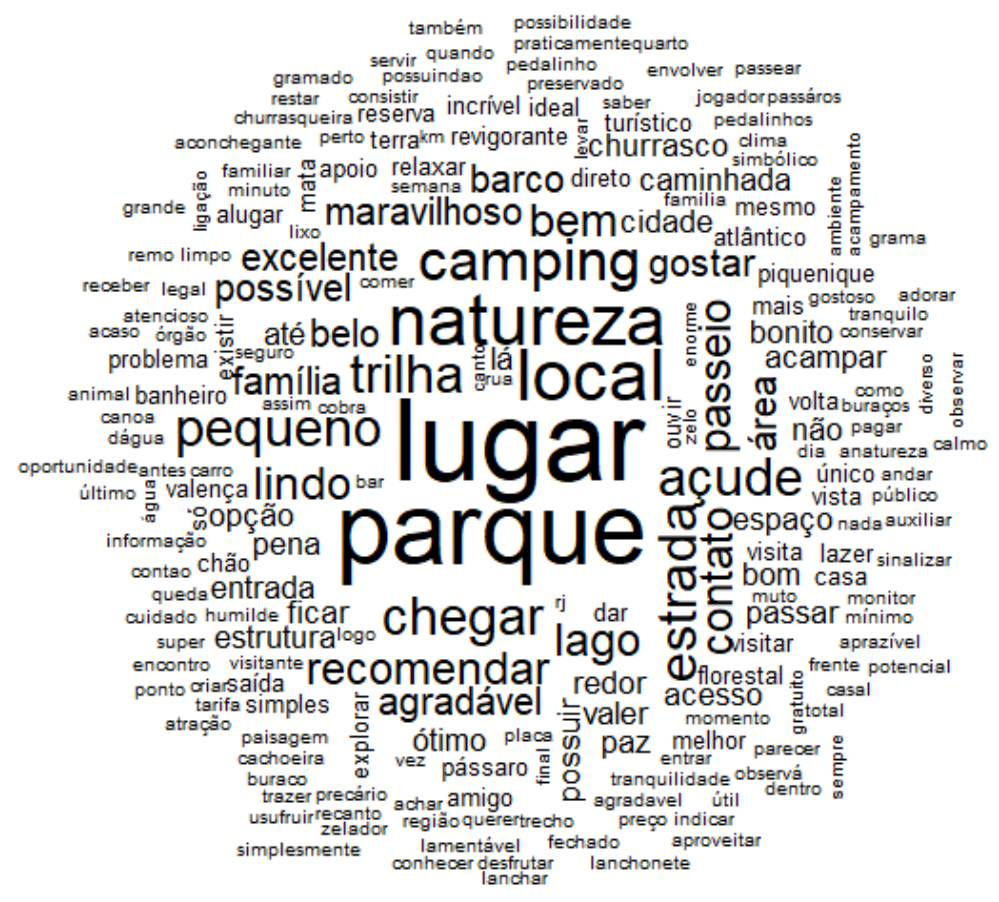

Fonte: Dados da pesquisa.

Em suma, a ênfase dos termos "local", "lugar" e "parque", na nuvem de palavras, decorre do esforço dos visitantes em tentar descrever os detalhes e características, sobretudo físicas, do atrativo. Não obstante, os termos "trilha", "camping" e "açude" ilustram as percepções quanto ao que se pode fazer no parque. Por fim, o termo "natureza", que aparece com significativo destaque, revela a perspectiva de que os turistas valorizam o contato com o meio ambiente preservado, o que notadamente é um trunfo na perspectiva do fomento às iniciativas de turismo sustentável.

Vale ponderar que as palavras "excelente", "maravilhoso" e "recomendar" sintetizam a perspectiva de que, pela ótica dos visitantes, o PaNaMAC oferece uma alternativa de turismo vista como adequada, o que normalmente implica altos níveis de satisfação por parte dos visitantes. Ademais, o termo "família" denota que, para boa parte dos visitantes, as 
opções de turismo que o parque oferece são adequadas para serem feitas na companhia de familiares.

Abaixo, há um trecho de um comentário, postado por um turista proveniente da cidade do Rio de Janeiro, que ilustra como "se percebe" o PaNaMAC:

Visitar esse parque é ter contato direto com a natureza. Lá há estrutura para um piquenique ou um churrasco, no lago é possivel andar de canoa, ou simplesmente fazer uma caminhada pelo gramado ouvindo os pássaros e observando os animais.

Percebe-se também, nos comentários, que há sugestões acerca de como o turismo poderia ser incrementado no PaNaMAC, conforme se depreende do trecho a seguir:

O parque tem um potencial turístico incrivel, porém o órgão público que cuida parece não estar sabendo aproveitar. Tem um lago maravilhoso que poderia servir para passeios de pedalinhos e barcos pequenos.

Portanto depreende-se que, na perspectiva dos visitantes, o PaNaMAC é um atrativo turístico considerado adequado, fonte de entretenimento e lazer para as pessoas que moram na região, e com potencial de difusão de iniciativas de turismo sustentável que necessariamente impliquem atividades em contato permanente com a natureza.

\section{CONSIDERAÇÕES FINAIS}

Afinal, quais os desafios no âmbito de planejamento e difusão de iniciativas de turismo sustentável no PaNaMAC?

Em síntese, os resultados levantados no presente estudo sinalizam que o caso sob análise tem considerável potencial para "abrigar" iniciativas de turismo sustentável, principalmente porque: o parque apresenta uma diversificada e importante fauna e flora ("protegida" em função de tratar-se de uma Unidade de Conservação), possui uma beleza cênica considerável, ao passo que também dispõe de uma estrutura mínima para que visitações aconteçam (há banheiros já construídos, deques, trilhas, áreas de camping e afins no parque). 
Não obstante, deve-se ainda considerar que os turistas que já visitaram - PaNaMAC sinalizam que as paisagens presentes na localidade são bonitas e aprazíveis, numa dinâmica em que o contato com a natureza evidencia o turismo sustentável enquanto algo potencial e muito promissor, no lócus sob análise.

Agora, considerando os aspectos sumarizados nos parágrafos anteriores, a questão que surge é: por que a modalidade de turismo sustentável não é uma realidade difundida no PaNaMAC, ante o potencial que a localidade apresenta?

A julgar pelos dados sumarizados no presente trabalho, parte-se da perspectiva de que o poder público é um dos principais responsáveis pela ausência de uma dinâmica mais vigorosa, no âmbito do turismo sustentável, no PaNaMAC. Os motivos que, em síntese, justificam a supracitada inferência são: (a) não há um planejamento estruturado e crível para a gestão do turismo, de um modo geral, e do turismo sustentável, em particular, no município de Valença - território em que o PaNaMAC se localiza; (b) inexistem análises concretas, confiáveis e pertinentes, acerca do PaNaMAC (tais como estudo de capacidade de carga, análise do perfil e número de turistas etc.), que subsidiem o planejamento e a gestão da atividade do turismo sustentável; (c) não se dispõe de uma estratégia coordenada de integração da comunidade local ao turismo sustentável; e (d) não há uma estrutura de apoio ao turista na localidade, tais como agências de turismo, hotéis, pousadas, restaurantes e empresas de transporte, que atuem de modo coordenado e sinérgico, em prol da difusão do turismo sustentável.

Para além da aparente apatia do poder público, deve-se registrar que as associações representativas de classe - tais como a Associação Brasileira de Bares e Restaurantes (Abrasel) e a Associação Brasileira da Indústria de Hotéis (Abih) -, ademais das organizações do terceiro setor, sobretudo aquelas ligadas à proteção do meio ambiente e populações tradicionais, mostram-se também ausentes do território, deixando vago um espaço que, eventualmente, poderia ser ocupado para que se coordenasse a difusão de iniciativas de turismo sustentável no PaNaMAC e na região de Valença como um todo. 
Entre as múltiplas ações que poderiam ser empreendidas para adequadamente planejar e difundir iniciativas de turismo sustentável no PaNaMAC e no município de Valença, especial destaque deve ser dado aos seguintes aspectos:

- Difundir o conceito de turismo sustentável para os integrantes do trade turístico do território, especialmente para aqueles responsáveis por planejar e gerir as iniciativas de turismo sustentável. Isso certamente permitirá a consolidação de maior consciência quanto à importância e aos desafios da implementação das iniciativas de turismo sustentável;

- Produzir estudos e análises quanto à capacidade de carga dos atrativos turísticos, perfil de turistas, além das principais atividades que podem ser empreendidas no escopo do turismo sustentável na localidade;

- Integrar a comunidade local nas iniciativas de turismo sustentável, fazendo com que os residentes locais também possam colher os bônus e, consequentemente, auxiliar na consolidação das ações de turismo sustentável;

- Estimular a integração do território e dos atrativos locais (tais como - PaNaMAC) nos roteiros já consolidados de turismo sustentável;

- Elaborar políticas públicas críveis, coordenadas, suprapartidárias e de longo prazo, que permitam com que o turismo sustentável integre uma agenda de Estado, fazendo com que existam estímulos permanentes que objetivem difundi-lo.

Os supracitados aspectos não implicam um esforço conclusivo, que "esgote" a temática explorada no presente artigo. Em suma, as ponderações acima apresentadas representam sugestões que poderiam ser implementadas no PaNaMAC para o fomento às iniciativas de turismo sustentável, assim como em outras realidades e Unidades de Conservação que também tenham potencial para a difusão da modalidade de turismo sob análise.

Novas investigações eventualmente explorando, com maiores detaIhes, a perspectiva dos turistas ou mesmo a perspectiva do ciclo das políticas públicas de turismo sustentável poderiam ser importantes, a fim de que a temática trabalhada neste artigo constitua uma verdadeira agenda de pesquisas e reflexões. 
Desafios no âmbito do planejamento e da difusão de iniciativas de turismo sustentável em uma Unidade de Conservação brasileira

\section{REFERÊNCIAS}

BARDIN, L. Análisis de contenido. 3. ed. Madrid: Ediciones Akal, 2002.

BARRETO, M. Manual de iniciação ao estudo do turismo. 17. ed. Campinas: Papirus, 2006.

CAMARGO, B. V.; JUSTO, A. M. Iramuteq: um software gratuito para análise de dados textuais. Revista Temas em Psicologia, v. 21, n. 2, p. 513-18, 2013.

CETIN, M. Evaluation of the sustainable tourism potential of a protected area for landscape planning: a case study of the ancient city of Pompeipolis in Kastamonu. International Journal of Sustainable Development \& World Ecology, v. 22, n. 6, p. 490-95, 2015. DOI: https://doi.org/10.1080/13504509.2015.1081651

DAMAS, M. T. Turismo sustentável: reflexões, avanços e perspectivas. Revista Brasileira de Ecoturismo, v. 13, n. 2, p. 310-27, 2020. DOI: https://doi.org/10.34024/ rbecotur.2020.v13.9578

HATIPOGLU, B.; ALVAREZ, M. D.; ERTUNA, B. Barriers to stakeholder involvement in the planning of sustainable tourism: the case of the Thrace region in Turkey. Journal of Cleaner Production, n. 111, p. 306-17, 2016. DOI: https://doi.org/10.1016/j. jclepro.2014.11.059

HIGGINS-DESBIOLLES, F. Sustainable tourism: sustaining tourism or something more? Tourism Management Perspectives, n. 25, p. 157-60, 2018.

INSTITUTO BRASILEIRO DE GEOGRAFIA E ESTATÍSTICA. Panorama de Valença, RJ. 2019. Disponível em: https://cidades.ibge.gov.br/brasil/rj/valenca/panorama . Acesso em: 28 abr. 2019.

INCHAUSTI-SINTES, F. Tourism: economic growth, employment and Dutch Disease. Annals of Tourism Research, n. 54, p. 172-89, 2015. DOI: https://doi.org/10.1016/j. annals.2015.07.007

KAMI, M. T. M. ; LAROCCA, L. M.; CHAVES, M. M. N.; LOWEN, I. M. V.; SOUZA, V. M. P.; GOTO, D. Y. N. Trabalho no consultório na rua: uso do software Iramuteq no apoio à pesquisa qualitativa. Escola Ana Nery, v. 20, n. 3, p. 1-5, 2016.

LEE, T. H.; JAN, F. H. Ecotourism behavior of nature-based tourists: an integrative framework. Journal of Travel Research, v. 57, n. 6, p. 792-810, 2018. 
LEMOS, M. S. O índio virou pó de café? A resistência dos índios Coroados de Valença frente à expansão cafeeira no Vale do Paraíba (1788-1836). 2004. 228 p. Dissertação (Mestrado em História) - Instituto de Filosofia e Ciências Humanas, Universidade do Estado do Rio de Janeiro (Uerj), Rio de Janeiro, RJ, 2004.

LIU, Z. Sustainable tourism development: a critique. Journal of Sustainable Tourism, v. 11, n. 6, p. 459-75, 2003. DOI: https://doi.org/10.1080/09669580308667216

MELLON, V.; BRAMWELL, B. Protected area policies and sustainable tourism: influences, relationships and co-evolution. Journal of Sustainable Tourism, v. 24, n. 10, p. 1369-86, 2016.

MELO, R. S.; MONTEIRO, M. S. L.; BRITO, A. S. Desenvolvimento turístico e sustentabilidade na Unidade de Conservação APA do Delta do Parnaíba (PI). Revista Brasileira de Ecoturismo, v. 11, n. 3, p. 335-61, 2018.

MERRIAM, S. B.; GRENIER, R. S. Qualitative research in practice: examples for discussion and analysis. 2. ed. San Francisco: Jossey-Bass, 2019.

MONGE, J. G.; PERALES, R. M. Y. El desarrollo turístico sostenible: Tren Crucero del Ecuador. Estudios y Perspectivas en Turismo, n. 25, p. 57-72, 2016.

MOWFORTH, M.; MUNT, I. Tourism and sustainability: development, globalization and new tourism in the Third World. London: Routledge, 2015. DOI: https://doi. org/10.4324/9781315795348

MURESAN, I. C.; OROIAN, C. F.; HARUN, R.; ARION. F. H.; PORUTIU, A.; CHICIUDEAN, G. O.; TODEA, A.; LILE, R. Local residents' attitude toward sustainable rural tourism development. Sustainability, v. 8, n. 1, p. 1-14, 2016. DOI: https://doi.org/10.3390/ su8010100

NILSSON, M.; GRIGGS, D.; VISBECK, M. Policy: map the interactions between Sustainable Development Goals. Nature, v. 534, n. 7607, p. 320-22, 2016.

RODRIGUES, J. G. V.; MOREIRA, S. A.; FREIRE, E. M. X. Entraves à efetivação de Unidades de Conservação: Parque Estadual Mata da Pipa, Tibau do Sul, RN, Brasil. Desenvolvimento e Meio Ambiente, n. 46, p. 109-32, 2018.

SANTOS, M. T.; MELO, I. B. N.; CARDOSO-LEITE, E. Análise do potencial e da demanda de visitação da Floresta Nacional de Capão Bonito (SP). Revista Brasileira de Ecoturismo, v. 12, n. 1, p. 36-54, 2019. 
Desafios no âmbito do planejamento e da difusão de iniciativas de turismo sustentável em uma Unidade de Conservação brasileira

SIGALA, M. A supply chain management approach for investigating the role of tour operators on sustainable tourism: the case of TUI. Journal of Cleaner Production, v. 16, n. 15, p. 1589-99, 2008. DOI: https://doi.org/10.1016/j.jclepro.2008.04.021

SOUSA, C. R.; AQUINO, C. M. S. Proteção ambiental e turismo no Parque Ambiental Encontro dos Rios, Teresina, PI. Caderno Virtual de Turismo, v. 7, n. 3, p. 66-74, 2007.

SOUZA, M. A. R.; WALL, M. L.; THULER, A. C. M. C.; LOWEN, I. M. V.; PERES, A. M. O uso do software Iramuteq na análise de dados em pesquisas qualitativas. Revista da Escola de Enfermagem da USP, n. 52, p. 1-7, 2018.

TEMOTEO, J. A. G., BRANDÃO, J. M. F.; CRISPIM, M. C. Turismo e sustentabilidade em Unidades de Conservação: um estudo sobre as alternativas de emprego e renda na Área de Proteção Ambiental da Barra do Rio Mamanguape-PB. Revista de Gestão Ambiental e Sustentabilidade, v. 7, n. 1, p. 43-61, 2018. DOI: https:// doi.org/10.5585/geas.v7i1.552

UNITED NATIONS. Our Common Future: report of world commission on environment and development. New York: UN, 1987.

URT, M. C. M.; ARRUDA, D. O.; MARIANI, M. A. P. Hotelaria de Charme e os desafios da agenda para o desenvolvimento sustentável no turismo. Revista Rosa dos Ventos - Turismo e Hospitalidade, v. 10, n. 1, p. 39-58, 2018. DOI: http://dx.doi. org/10.18226/21789061.v10i1p39

VAZ, D. M. S. Perfil dos visitantes do Parque Natural Municipal do Açude da Concórdia - Valença (RJ). Revista Brasileira de Ecoturismo, v. 3, n. 1, p. 109-20, 2010.

WONG, I. A.; LAW, R.; ZHAO, X. Time-variant pleasure travel motivations and behaviors. Journal of Travel Research, v. 57, n. 4, p. 1-16, 2018.

WORLD TOURISM ORGANIZATION. UNWTO Annual Report. Madrid, Spain: Unwto, 2018. DOI: https://doi.org/10.18111/9789284419807

WORLD TOURISM ORGANIZATION. Guide for local authorities on developing sustainable tourism. Madrid, Spain: Unwto, 1998.

WORLD TRAVEL AND TOURISM COUNCIL. Travel \& Tourism - Economic Impact 2019 - World. London: WTTC, 2019.

YIN, R. K. Estudo de caso: planejamento e métodos. 5. ed. Porto Alegre: Bookman, 2015. 
